\title{
Innovative Approaches to Building Resilient Coastal Infrastructure
}

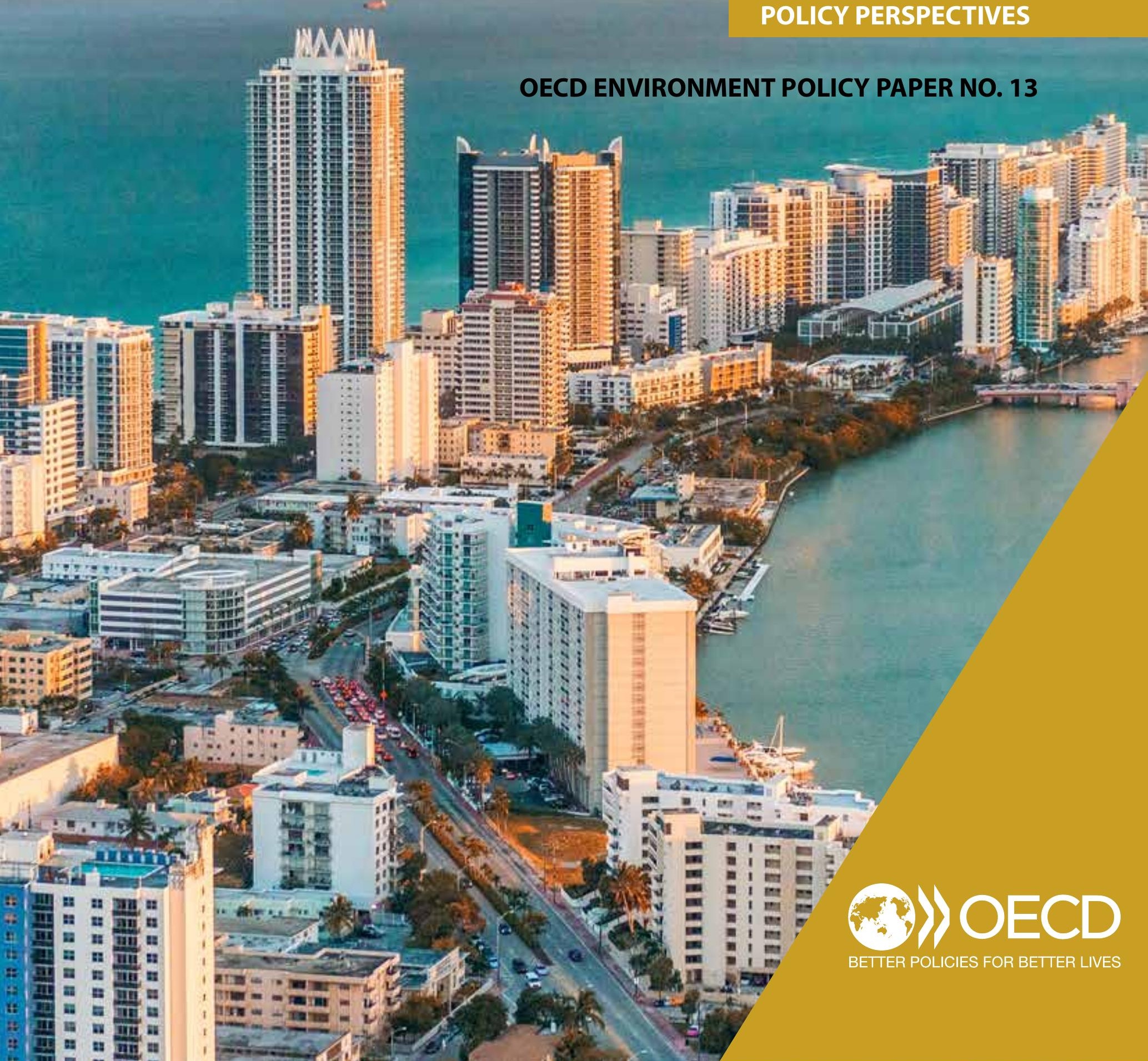


This Policy Paper comprises an Issue Brief and Background Report prepared by the OECD for the G7 Environment, Energy and Oceans Ministers. It outlines the rising risks faced by coastal communities, which are being exacerbated by climate change. It shows how governments can harness innovation in information, planning, financing and monitoring to help improve resilience of those areas to climate change, and emphasises the need for close engagement with coastal communities.

\section{Disclaimers}

This paper is published under the responsibility of the Secretary-General of the OECD. The opinions expressed and the arguments employed herein do not necessarily reflect the official views of OECD member countries.

This document and any map included herein are without prejudice to the status of or sovereignty over any territory, to the delimitation of international frontiers and boundaries and to the name of any territory, city or area.

For Israel, change is measured between 1997-99 and 2009-11. The statistical data for Israel are supplied by and under the responsibility of the relevant Israeli authorities. The use of such data by the OECD is without prejudice to the status of the Golan Heights, East Jerusalem and Israeli settlements in the West Bank under the terms of international law.

\section{Copyright}

You can copy, download or print OECD content for your own use, and you can include excerpts from OECD publications, databases and multimedia products in your own documents, presentations, blogs, websites and teaching materials, provided that suitable acknowledgment of OECD as source and copyright owner is given. All requests for public or commercial use and translation rights should be submitted to rights@oecd.org. Requests for permission to photocopy portions of this material for public or commercial use shall be addressed directly to the Copyright Clearance Center (CCC) at info@copyright.com or the Centre français d'exploitation du droit de copie (CFC) at contact@cfcopies.com.

Image credits: pisaphotography (cover); Michael Mullan (p. b)

\section{(C) OECD 2018}

ISSN 2309-7841

Authorised for publication by Rodolfo Lacy, Director, Environment Directorate

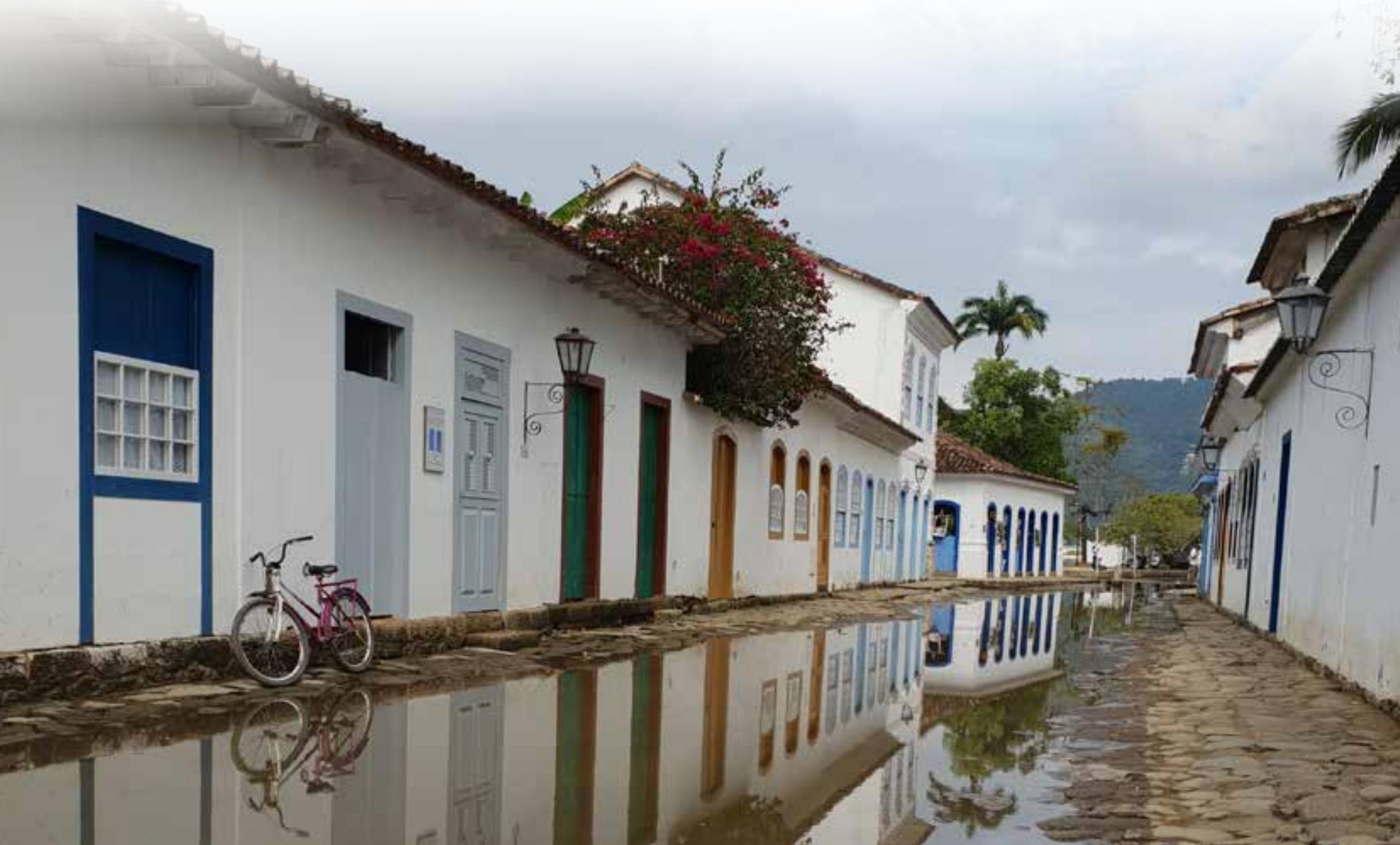




\section{에 $O E C D$}

\section{Innovative Approaches to Building Resilient Coastal Infrastructure}

Background Report

Prepared by the OECD for the G7

Environment, Energy and Oceans Ministers

September 2018 


\section{Resilient coastal infrastructure: setting the scene}

1. People have long been drawn to coastal zones for their transport links, amenity value and access to marine resources. Today over $40 \%$ of the global population live near the sea ${ }^{1}$. While being located on the coast has many benefits, it also exposes people and assets to associated hazards. These hazards include both large-scale, rapid-moving disturbances such as storm surges, and slowonset changes, including coastal land subsidence, erosion and the degradation of ecosystem services. Recent events have demonstrated how devastating these hazards can be: according to preliminary estimates Hurricanes Harvey, Irma and Maria led to damages of more than USD 265 billion and 247 deaths, predominantly in coastal areas ${ }^{2}$.

2. Climate change is a risk multiplier for coastal areas. The Intergovernmental Panel on Climate Change's Fifth Assessment Report ${ }^{3}$ (2014) estimates that global mean sea-level rise could reach 1 metre by the end of the century in a high emissions scenario, while more recent projections suggest that it could go beyond 2 metres by $2100^{4}$. As risks increase, so will the associated economic, human and environmental costs from extreme events and slow-onset changes. Even in the absence of climate change impacts, projections show that due to population growth and urbanisation total flood losses could increase to USD 52 billion per year by 2050 averaged across 136 of the world's largest coastal cities $^{5}$. Climate change impacts also have distributional implications across people and places, with developing countries, including Small Island Developing States (SIDS), being particularly vulnerable $^{6}$. Socio-economic vulnerability and pre-existing inequalities, including gender inequality, mean that some communities and individuals are more acutely affected by increasing coastal risks than others.

3. The core challenge for creating coastal resilience ${ }^{7}$ is that adaptation measures need to accommodate increasing risk, heightened by deep uncertainty, in areas with heterogeneous stakeholders with different priorities. Coastal adaptation measures include protecting coastlines from flooding and erosion, building new infrastructure - or retrofitting existing infrastructure - to better withstand and quickly recover from extreme weather events, and hazard-based land use planning. These all have the ability to significantly reduce future costs related to climate change. However, in the context of rising risks, there is a need to move beyond a heavy reliance on hard coastal defences (e.g. seawalls) designed to manage current or historic risks, to a more flexible, forward-looking approach. This includes integrating hard infrastructure with nature-based solutions (e.g. protection or restoration of coastal ecosystems), new technologies for accommodating flood risk (e.g. permeable pavement), and potential managed retreat in some areas.

4. While hard infrastructure may be the most feasible or cost-effective approach in some contexts, such as highly dense cities, building and maintaining hard infrastructure across all exposed coasts is not financially viable, and in some cases, may be technically impossible ${ }^{8}$. Hard infrastructure can also negatively affect biodiversity, coastal ecosystems, and the services they provide, further increasing coastal vulnerability ${ }^{9}$. Finally, the construction of protective infrastructure can create a cycle of coastal development and increased protection. Once structural protection is built, the perception of increased safety can lead to further development in the flood zone, which can have the perverse impact of increasing vulnerability in the longer-term. If those defences then fail, the results can be catastrophic ${ }^{10}$.

5.

Ageing and obsolete infrastructure in G7 countries needs to be upgraded and rebuilt, providing a unique opportunity to ensure that coastal infrastructure is resilient to the current and future climate. However, a resilient future requires innovative approaches not only from a technical point of view (e.g. "natural" v. "built" infrastructure), but also in terms of process, design, decision making and organisation, with a focus on who does what, how and at what cost. 


\section{Innovation for resilient coastal communities}

6. This paper explores how governments can apply innovative solutions across all stages of the infrastructure planning cycle: from assessing risks to adjusting responses, if need be (Figure 1). In practice, this means: using new ways to understand and communicate climate risk, encouraging innovative forms of planning, mobilising new sources of finance for coastal projects and monitoring coastal infrastructure management. Engaging local communities is fundamental to each stage.

Figure 1. Infrastructure planning and construction cycle

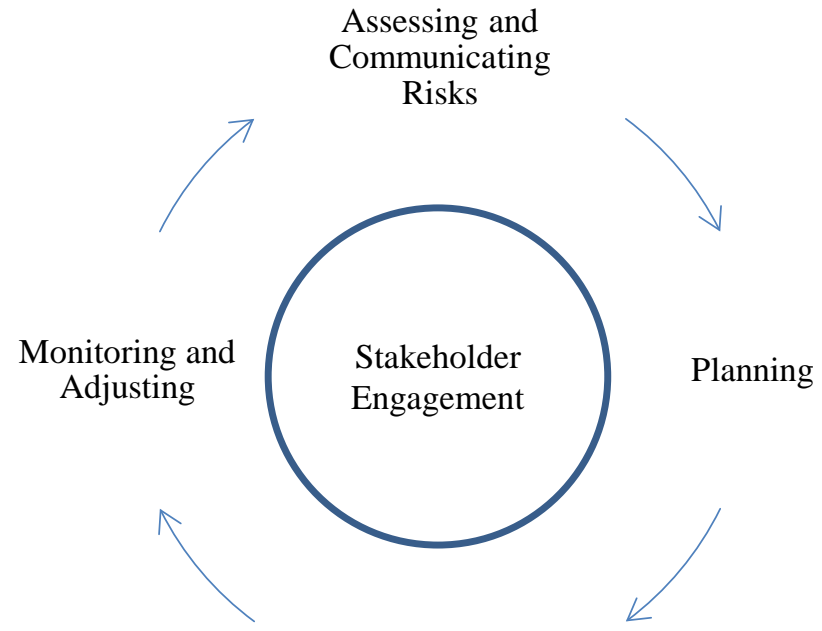

Financing

7. A resilient coastal community is one that is prepared for a range of future scenarios and can adapt to change in a sustainable, integrated and inclusive way, at an acceptable cost. This means adaptation measures need to build in flexibility, take advantage of co-benefits (such as the creation of space for recreation and nature), and involve diverse stakeholders for awareness raising, decision making and policy implementation. G7 countries ${ }^{11}$ are already starting to use innovative approaches to manage coastal risk:

- In New York City, the East Side Coastal Resiliency Project aims to protect the urban coastline against floods and rising sea levels during extreme high-tide events, while also providing waterfront access, improved public spaces and enhanced natural areas;

- In the UK, the process of managed realignment (e.g. managed retreat) deliberately shifts the line of built defences back from the coast, creating new wetland ecosystems and recreational areas while achieving higher standards of protection;

- In France, under the Integrated Coastline Management Strategy, certain local projects have focussed on restoring natural ecological processes to coastal areas whilst experimenting with the resettlement of people and assets most at risk. 


\section{Assessing and communicating risk}

8. Access to credible and transparent climate projections and risk information is essential for coastal resilience. Decisions about location, timing, and design of coastal adaptation responses require trustworthy information about coastal hazards, exposure and vulnerabilities. In addition, scientific information needs to be clearly communicated and understood by affected stakeholders to build a common vision and strategy for greater resilience. Some sources of information are already available, such as projections of future global sea levels by the International Panel on Climate Change (IPCC), and many OECD countries have produced their own national-level climate projections ${ }^{12}$. However, sea-level rise is among the most uncertain of climate impacts, both in terms of the magnitude of related future events (due to the contribution of the Greenland and Antarctic ice sheets), as well as the variation in regional distribution ${ }^{13}$.

9. Decision makers, including national policy makers, regulators, the private sector and local governments need both the tools and capacity to use climate data for decision making ${ }^{14}$. Best practices that governments could scale up include:

- Integrating climate change risks into maps: Improving data availability on current levels of extreme events, recent trends and projections of future changes into hazard maps ${ }^{15}$. In regions where information has been integrated, this can be used to inform regulations - for example, the City of Vancouver, Canada, changed its minimum flood construction levels to account for rising seas ${ }^{16}$.

- Systematically assessing vulnerability: In general, hazard assessments are tailored towards the needs of land-use planning (e.g. to inform the designation of land-use restrictions $)^{17}$. However, information about vulnerability and exposure of people and assets that explicitly considers climate change is crucial to prioritize and respond to sea-level rise risks ${ }^{18}$. While some countries do produce assessments that take exposure and vulnerability into account, overall they are not commonly available as they can be resource-intensive to produce and update ${ }^{19}$.

- Identifying and managing risks arising from interdependencies between infrastructure assets: Infrastructure systems can be interdependent (e.g. water treatment plants need electricity from the grid to function, and ports require nearby roads or railways to be accessible to transport goods or passengers), which means that climate change impacts on one infrastructure asset can cascade through the system. Climate risk assessments can be strengthened by mapping interdependencies across critical infrastructure and adopting a multi-sector, multi-hazard approach ${ }^{20}$. Effective collaboration and information sharing among key public and private infrastructure organisations in different sectors (e.g. transport and energy) is critical for understanding and addressing these shared risks.

10. The growing demand for easy-to-use climate information and risk management services has created new business opportunities ${ }^{21}$. Both public and private sector entities are developing online platforms and data portals to improve user access to multiple data sets, and deliver customised risk assessments. Some governments, particularly at the municipal level, are entering into innovative partnerships with the private sector to make use of the significant risk assessment expertise developed to support insurance coverage of coastal risks. For example, in 2016, the City and County of San Francisco released a comprehensive action plan for addressing sea-level rise informed by private sector catastrophe modelling ${ }^{22}$. However, for any of these platforms to work effectively, it is important that there is transparency about the underlying data and their limitations. 


\section{Planning resilient coastal infrastructure}

11. Public policy and regulation play a key role in enabling and promoting innovative coastal resilience. In general, existing regulations and permitting processes do not take into account the evolving risks associated with climate change and were developed with hard infrastructure in mind, so alternative approaches can face higher upfront costs and regulatory barriers. These approaches include nature-based solutions, such as habitat protection and restoration; hybrid approaches, that combine hard infrastructure with nature-based solutions; and new technologies to accommodate flood risk, such as using permeable paving materials. Actions that could be scaled up include:

- Integrating climate risk into decision making at an early stage of planning: This can help to minimise downstream maintenance costs, and avoid increasing future vulnerabilities. For example, land-use planning can help reduce exposure to climate hazards by determining the possible locations for different types of development. It can also facilitate nature-based approaches to adaptation by maintaining restrictions or creating incentives that protect ecosystems (e.g. wetlands and forests) and ensure the ongoing provision of ecosystem services such as flood defence and erosion control. In almost all cases, preserving existing coastal ecosystems is more cost-effective than restoring degraded ecosystems or building up new ones ${ }^{23}$.

- Developing new standards, or modifying existing ones, to better account for a changing climate: For example, some countries have created a sea-level rise safety margin for coastal defence infrastructure ${ }^{24}$. However, there is a tension that needs to be managed: establishing consistent, straightforward standards, while at the same time considering the uncertain and context-specific nature of climate risks, all the while making space for alternative approaches. Governments need to ensure standardised approaches do not lead to systematic over- or under-investment in resilience ${ }^{25}$.

- Fostering the potential of the private sector by structuring policies that encourage innovation in resilient infrastructure planning and design: For example, public procurement policies can facilitate innovation in the provision of climate-resilient infrastructure by specifying objectives rather than mandating the use of specific technologies ${ }^{26}$. For Public Private Partnership (PPP) contracts, it is important to clarify the allocation of responsibilities regarding climate-related risks in planning, management and response ${ }^{27}$. Physical climate risk disclosure ${ }^{28}$, as detailed below, has the potential to encourage private sector innovation, by informing investment decisions, raising awareness within organisations about their exposure to climate risks, and stimulating action to reduce those risks ${ }^{29}$.

- Addressing policy misalignments that distort incentives and potentially discourage innovation: For example, real estate values - and in some cases, insurance premiums do not always reflect rising coastal risks. This can distort incentives for local authorities who accrue most of the benefits of new development, while the costs of extreme events are usually shared with regional or national governments ${ }^{30}$. This short-term economic incentive can lead to development in increasingly risky areas, storing up risks and hidden costs for the future. Well-aligned policies also play a critical role in managing the range of pressures that affect ecosystem health, and therefore overall resilience. 


\section{Mobilising additional sources of investment for coastal resilience}

12

Investment needs in coastal resilience are increasing globally, due to coastal development and sea-level rise. Minimum estimates for building hard coastal protective infrastructure (e.g. seawalls) alone project between roughly USD 10 billion in the near term and up to USD 70 billion annually by the end of the century ${ }^{31}$. The majority of funding currently comes from the public sector, but is insufficient to cover projected needs. This is representative of a broader gap between infrastructure needs and trends in infrastructure investment, in part due to the trend of underinvestment in infrastructure that has occurred over the past decades ${ }^{32}$.

13. Additional sources of investment (including institutional investors, private banking, and philanthropists) need to be mobilised to fill the coastal adaptation financing gap. The key challenge in mobilising investment for coastal resilience is the absence of mechanisms to convert the benefits of coastal resilience into predictable and clearly identifiable revenue streams. This is combined with the lack of tested business models for financing up-front investments. In addition to the lack of information and misaligned policies outlined in the previous sections of this paper, the following barriers hinder investment in coastal resilience:

- Time horizons: often the impacts from climate change, and associated contingent liabilities, lie beyond the time horizons considered by investors and other decision makers;

- Market failures: resilient investments may give rise to positive externalities that are not priced by the market, or some of the benefits may be "public goods" (such as increased protection from coastal hazards, and biodiversity) that can be underprovided by the market;

- Inequality: the potential beneficiaries of improved resilience may lack the political voice or resources to advocate for investments in resilience. This is a particular challenge given that vulnerability to climate change is associated with and exacerbated by poverty and social exclusion.

14. A number of approaches can help governments overcome these barriers and scale up investments in resilient coastal infrastructure:

- Encouraging recognition of the expected costs linked to coastal risks as contingent liabilities, in order to put a price on the benefits of risk reduction: In most cases, countries spend far more on disaster response than disaster prevention ${ }^{33}$, even though resilience investments have a high cost-return ratio. Coastal risks have costs that go far beyond the public sector. Climate change can have impacts on the operational, environmental and social performance of physical assets and infrastructure and overall market conditions, e.g. through asset deterioration and reduced life span. Mechanisms that help to raise awareness and price risk, such as coastal flood insurance and physical climate risk disclosure, can go a long way in encouraging upfront investment in resilience and adaptation.

o Innovations in spatial sciences and big data are making it possible for the insurance industry to improve their assessment of risk, allowing for more granular pricing. This can prompt individuals, businesses and local governments to take efforts to increase their resilience in order to reduce their insurance costs. Innovations are also allowing for the development of new types of insurance coverage, such as products that recognize the resilient value of nature-based interventions. In Cancún, Mexico, insurance is being linked with the protection of a coral reef, as it is estimated that a one-meter loss of reef height could translate into USD 20 billion in lost infrastructure in Mexico ${ }^{34}$. 
o Relevant initiatives are being developed to support emerging practices in physical climate risk disclosure. For example, the G20 mandated Task Force on Climaterelated Financial Disclosure (TCFD) recommends the reporting of, inter alia, physical risks relating to the impacts of climate change, with a focus on the following areas: governance, risk management, strategy and metrics ${ }^{35}$. In France, Article 173 requires that listed companies report on climate change impacts, or explain why they have not done so. Companies are encouraged to include disclosure of physical climate risks in their reports.

- Using economic instruments to capture the positive externalities of coastal investments: For example, Payments for Ecosystem Services (PES) ${ }^{36}$ can be used to encourage conservation and restoration of coastal ecosystems, and create natural buffer zones between coastal and terrestrial habitats. Similarly, differential tax rates for coastal properties can be used to fund coastal protection projects, such as beach nourishment, that benefit specific areas. However, increasing protection in one area of the coast has the potential to increase erosion and therefore vulnerability in another. There is a strong role for government to coordinate efforts.

- Scaling up finance for coastal resilience in SIDS and other vulnerable developing countries: The lack of investment in resilient infrastructure in developing countries is in part due to actual and perceived risks with respect to political instability, poor investment environments and currency risks. Development co-operation has a significant role to play in supporting partner countries in building coastal resilience. This support is especially important for SIDS, for which concessional finance remains a vital source of financing, given challenges in mobilising domestic and other external sources of finance. The proportion of concessional finance that fosters development that is resilient to the impacts of climate change and natural disasters is also low, making up only $14 \%$ of concessional finance to SIDS over 2011-2014 ${ }^{37}$.

o Innovative approaches are emerging to address this: for example, the first climate adaptation debt restructuring was agreed between the Government of Seychelles and Paris Club creditors, where part of the debt service payments fund improved management of coral reefs and mangroves. Another example is blended finance, which can be used to help reduce and allocate risks sufficiently to attract private capital to resilient coastal infrastructure ${ }^{38}$. The Caribbean Investment Facility, established by the European Union, combines grants from the European Development Fund with other public and private resources to support infrastructure projects in SIDS. Adhering to strong policy principles and standards can help ensure that blending approaches crowd-in investment without distorting markets ${ }^{39}$.

- Advancing the adoption of disaster risk financing strategies in the most vulnerable countries: Even with investments in coastal resilience, extreme events will still cause acute damage and service disruptions. In such cases, financial protection measures, such as insurance, play a key role. If properly designed, risk-financing strategies can help people cope with the impacts of climate-related disasters, reduce costs of and delays in recovery and reconstruction, and encourage risk reduction (by enhancing risk understanding and recognising cost-benefit of risk reduction) ${ }^{40}$.

0 There are a number of initiatives ${ }^{41}$ aimed at enhancing coverage for disaster risks, both for individuals and governments. Financial innovations, such as catastrophe bonds and regional risk pools, are providing more capacity to cover these risks. However, high risk profiles and limited recognition of contingent liabilities reduces demand, and 
therefore supply, of these instruments ${ }^{42}$. The recently adopted OECD Recommendation on Disaster Risk Financing Strategies provides guidance to governments on how to design a strategy for managing the financial impacts of disasters, including by leveraging the contribution of insurance and other risk transfer instruments.

\section{Monitoring and adjusting infrastructure plans for a changing climate}

15.

In an uncertain future, it is particularly essential to monitor and adjust coastal resilience measures in light of changing environmental circumstances and increasing knowledge and experience. Given the long lifetimes of coastal projects, it is important to take early action to integrate adaptation into decision making, but also to ensure flexibility or robustness to address future uncertainty. Monitoring is best integrated from the outset to avoid entrenching current exposure to hazards or incurring larger than necessary adjustment costs in the future. However, a number of challenges in monitoring for adaptation, including long timeframes, uncertainty regarding impacts at the local level, difficulties in establishing baselines and targets, and the challenge of discerning cause and effect ${ }^{43}$. Monitoring responses can also be resource intensive, particularly the human and technical capacities required to collect and accurately interpret data ${ }^{44}$.

16. Most OECD countries have indicated within their adaptation plans that they plan to design and implement a monitoring and evaluation system at the national level, but relatively few systems are currently operational ${ }^{45}$. To date, adaptation monitoring and evaluation remains far more common at the project and programme level ${ }^{46}$. In the UK, an evaluation of the effectiveness of their Shoreline Management plans resulted in a modified approach to coastal zone management from a purely reactive one to a more overtly proactive approach ${ }^{47}$. Ongoing monitoring of projects' effectiveness is especially important for innovative coastal interventions. In contrast to traditional approaches to coastal protection, many innovative approaches were implemented only recently. And in many cases, there remains a lack of data on effectiveness or cost-benefit ratios, which can hinder wider uptake.

17. To ensure coastal infrastructure plans are dynamic and can be adjusted with changing conditions, governments could:

- Use iterative decision making processes that can be adjusted over time as more information becomes available;

- Consider how short-term actions potentially enable or obstruct future options. Take steps to avoid inefficient path dependencies or costly infrastructure retrofits; and,

- Identify actions that promote flexibility, and provide opportunities to shift among options depending on evolving trends (e.g. climatic, demographic, technological) ${ }^{48}$.

\section{Engaging stakeholders for enhanced coastal resilience}

18. Stakeholder engagement at all stages of the infrastructure cycle is fundamental for ensuring coastal resilience (Table 2). Seeking input, guidance and leadership on projects and plans through participatory decision making with community members (e.g. local, indigenous, remote coastal and small island communities), can enhance overall resilience in coastal areas, while also supporting community ownership and buy-in. It can also empower specific groups (women, youth, etc.) during recovery. 
Table 2. Infrastructure cycle and stakeholder engagement

\begin{tabular}{|c|c|}
\hline Phase & Objectives of stakeholder engagement and examples of mechanisms \\
\hline Assessing & $\begin{array}{l}\text { Identification of risks to different categories of stakeholders and assets; information provision (e.g. } \\
\text { through perception-based surveys) for climate risk assessments and adaptation planning }\end{array}$ \\
\hline Planning & $\begin{array}{l}\text { Development of a common vision for the development of resilient coastal infrastructure, through } \\
\text { consultations, and a range of stakeholder engagement mechanisms } 49\end{array}$ \\
\hline Financing & Enhancing the willingness to pay for innovative project and identifying new sources of finance \\
\hline Monitoring & $\begin{array}{l}\text { Multi-stakeholder meetings and ad hoc surveys to help monitor social, environmental and economic } \\
\text { impacts of coastal infrastructure, as well as of the stakeholder process itself }\end{array}$ \\
\hline
\end{tabular}

19. Drawing from the OECD literature on stakeholder engagement ${ }^{50}$, some practices to be considered for enhancing resilience in coastal infrastructure are:

- Engagement needs to reach out beyond usual stakeholders: If properly engaged, some stakeholders can be key sources of information or provide new sources of finance. For instance, local knowledge drawing on the perspectives of diverse stakeholders can help identify vulnerabilities and impacts that may not be well-known because of the highly contextual nature of climate risk. This can also be the case of indigenous people, which constitute a specific category of stakeholders in some cases constitutionally protected, as in Canada. Property developers are another key stakeholder group for coastal adaptation. As spatial development can generate long-term liabilities and financial implications in terms of coastal flood management, engaging developers can bring about new sources of finance if the right business models are in place.

- Engagement processes and mechanisms should accommodate the needs of stakeholders with varying levels of interest and resources to ensure inclusivity and accessibility: Stakeholder engagement ranges from communication to consultation, participation, representation, partnerships, and co-production or co-decision. The relevant level and channel of engagement has to be determined according to the intended objectives, which have to be defined and specified upfront. Mechanisms for engagement should be chosen according to the types of stakeholders, the specific matter and the local context. These mechanisms (formal or informal) should avoid consultation capture from over-represented groups. For instance, coastal property owners typically have a stake in influencing coastal decision making and can potentially block measures that reduce the value of their property. On the other hand, vulnerable stakeholder groups (women, youth, indigenous groups etc.) are often not engaged in decision-making processes relevant for resilience and disaster risk reduction, even though they tend to be disproportionately exposed to climate risks. The same holds true for the post disaster phase.

- Assess community engagement processes and outcomes for coastal infrastructure investment to improve and adjust as need be: Multi-stakeholder meetings, ad hoc surveys, perception-based tools and indicators can help monitor social, environmental and economic impacts of coastal infrastructure, strengthen the accountability of decision makers and anticipate risks. The assessment should be carried out before, during and after the engagement process and results should be shared to increase transparency and accountability. The aim would be to capture the costs and benefits of stakeholder engagement. A checklist and indicators can help customise the type and level of engagement as needed and keep the process flexible to changing circumstances. Countries should invest in and report on stakeholder group (such as women and girls) data and 
analysis. This will make it possible to deliver more effective responses to disaster events, while taking into account-and responding to — the unique needs of these groups.

20. Local authorities play an important role in promoting and facilitating stakeholder engagement in setting and implementing policies for enhanced coastal resilience. However, coordination across levels of government is needed to build synergies and avoid overlaps. For instance, government could review legal and policy frameworks, organisational structures/principles and responsible authorities to ensure they are conducive to effective stakeholder engagement processes. It is important for countries to define mechanisms for local community engagement, map the stakeholders, their responsibilities, motivations and interactions as well as to define the ultimate line of decision making, the objectives of local community engagement and the expected use of inputs.

\section{Concluding remarks}

21. There is robust evidence and a compelling case on the need to enhance coastal resilience. While not all coastal risks can be avoided, well-prepared coastal communities will be better able to adjust to new conditions, at lower cost, and rapidly bounce back from disasters when they occur. Governments can harness innovation in information, planning, financing and monitoring to help improve the resilience of our coasts to climate change. Yet, experience has shown that increasing scientific evidence and a strong economic argument alone do not necessarily spur action. Implementing change takes time, stakeholder engagement, and political will, and needs to be a continuous process of acting, learning and changing course if necessary. This sets an urgent need for countries to put in place now the policies needed to prepare for the future. 


\section{References and notes}

${ }^{1}$ United Nations (2007), Indicators of Sustainable Development: Guidelines and Methodologies-Third edition Methodology sheets, United Nations, http://www.un.org/esa/sustdev/natlinfo/indicators/methodology sheets.pdf (accessed on 01 August 2018).

2 NOAA (2018), Billion-Dollar Weather and Climate Disasters: Table of Events, https://www.ncdc.noaa.gov/billions/events/US/2017 (accessed on 01 August 2018).

${ }^{3}$ Wong, P. et al. (2014), Coastal Systems and Low-Lying Areas, IPCC, https://www.ipcc.ch/pdf/assessmentreport/ar5/wg2/WGIIAR5-Chap5_FINAL.pdf

${ }^{4}$ Oppenheimer, M. and R. Alley (2016), “How high will the seas rise?”, Science (New York, N.Y.), Vol. 354/6318, pp. 1375-1377, http://dx.doi.org/10.1126/science.aak9460.

${ }^{5}$ OECD and Bloomberg Philanthropies (2014), Cities and Climate Change. Policy Perspectives: National Governments enabling local action, OECD, Paris, www.oecd.org/env/cc/Cities-and-climate-change-2014-Policy-Perspectives-Finalweb.pdf (accessed 01 August 2018).

${ }^{6}$ OECD (2018), Making Development Co-operation Work for Small Island Developing States, OECD Publishing, Paris, https://doi.org/10.1787/9789264287648-en.

7 “The capacity of social, economic and environmental systems to cope with a hazardous event or trend or disturbance, responding or reorganizing in ways that maintain their essential function, identity and structure, while also maintaining the capacity for adaptation, learning and transformation" (IPCC AR5). Climate change adaptation is the process of building resilience to the impacts of climate change.

${ }^{8}$ Hinkel, J. et al. (2014), “Coastal flood damage and adaptation costs under 21st century sea-level rise.”, Proceedings of the National Academy of Sciences of the United States of America, Vol. 111/9, pp. 3292-7,

http://dx.doi.org/10.1073/pnas.1222469111.

${ }^{9}$ Narayan, S. et al. (2016), “The Effectiveness, Costs and Coastal Protection Benefits of Natural and Nature-Based

Defences”, PLOS ONE, Vol. 11/5, p. e0154735, http://dx.doi.org/10.1371/journal.pone.0154735.

${ }^{10}$ OECD (2014), Water Governance in the Netherlands: Fit for the Future?, OECD Studies on Water, OECD Publishing, Paris, http://dx.doi.org/10.1787/9789264102637-en.

${ }^{11}$ Canada, France, U.S., U.K., Germany, Japan, Italy

${ }^{12}$ Vallejo, L. and M. Mullan (2017), “Climate-resilient infrastructure: Getting the policies right”, OECD Environment Working Papers, No. 121, OECD Publishing, Paris, http://dx.doi.org/10.1787/02f74d61-en.

${ }^{13}$ Wong, P. et al. (2014), Coastal Systems and Low-Lying Areas, IPCC, https://www.ipcc.ch/pdf/assessmentreport/ar5/wg2/WGIIAR5-Chap5_FINAL.pdf

${ }^{14}$ OECD (2016), Financial Management of Flood Risk, OECD Publishing, Paris, http://dx.doi.org/10.1787/9789264257689-en.

${ }^{15}$ OECD (2017), Boosting Disaster Prevention through Innovative Risk Governance: Insights from Austria, France and Switzerland, OECD Reviews of Risk Management Policies, OECD Publishing, Paris,

http://dx.doi.org/10.1787/9789264281370-en.

${ }^{16}$ OECD (forthcoming), Comparative approaches to sea-level rise

17 OECD (2016), Financial Management of Flood Risk, OECD Publishing, Paris, http://dx.doi.org/10.1787/9789264257689-en.

${ }_{18}$ OECD (2017), Boosting Disaster Prevention through Innovative Risk Governance: Insights from Austria, France and Switzerland, OECD Reviews of Risk Management Policies, OECD Publishing, Paris, http://dx.doi.org/10.1787/9789264281370-en.

${ }^{19}$ OECD (2016), Financial Management of Flood Risk, OECD Publishing, Paris, http://dx.doi.org/10.1787/9789264257689-en.

${ }^{20}$ OECD (2014), Boosting Resilience through Innovative Risk Governance, OECD Reviews of Risk Management Policies, OECD Publishing, Paris, http://dx.doi.org/10.1787/9789264209114-en

${ }^{21}$ OECD (2018), Climate resilient infrastructure, forthcoming

${ }^{22}$ City and County of San Francisco (2016), San Francisco Sea Level Rise Action Plan, http://sf-planning.org/sea-levelrise-action-plan (accessed on 01 August 2018).

${ }^{23}$ Bayraktarov, E. et al. (2016), “The cost and feasibility of marine coastal restoration”, Ecological Applications,

Vol. 26/4, pp. 1055-1074, http://dx.doi.org/10.1890/15-1077.

${ }^{24}$ OECD (forthcoming), Comparative approaches to sea-level rise 
${ }^{25}$ OECD (2018), Climate resilient infrastructure, forthcoming

${ }^{26}$ Baron (2016), “The Role of Public Procurement in Low-carbon Innovation”, OECD Publishing

${ }^{27}$ Vallejo, L. and M. Mullan (2017), “Climate-resilient infrastructure: Getting the policies right”, OECD Environment Working Papers, No. 121, OECD Publishing, Paris, http://dx.doi.org/10.1787/02f74d61-en.

${ }^{28}$ This brief focuses on physical climate risks, which can be event driven (acute) or longer-term shifts (chronic) in climate patterns. These are different from transition risks, which are financial risk associated with the transitions to low GHG economies.

${ }^{29}$ Task Force on Climate-Related Financial Disclosures (2017), Recommendations of the Task Force on Climate-related Financial Disclosures i, https://www.fsb-tcfd.org/wp-content/uploads/2017/06/FINAL-TCFD-Report-062817.pdf

${ }^{30}$ OECD (2014), Boosting Resilience through Innovative Risk Governance, OECD Reviews of Risk Management Policies, OECD Publishing, Paris, http://dx.doi.org/10.1787/9789264209114-en.

${ }^{31}$ Hinkel, J. et al. (2014), “Coastal flood damage and adaptation costs under 21st century sea-level rise.”, Proceedings of the National Academy of Sciences of the United States of America, Vol. 111/9, pp. 3292-7,

http://dx.doi.org/10.1073/pnas.1222469111.

${ }^{32}$ OECD (2018), Climate resilient infrastructure, forthcoming

33 (Forthcoming) OECD and World Bank

34 The Nature Conservancy (2018), Launch of the Coastal Zone Management Trust, https://thought-leadershipproduction.s3.amazonaws.com/2018/03/08/14/23/46/1ac3a4be-11d2-4651-9d98-

50326d81e1b8/TNC_Mexico_CoastalManagementTrust_Factsheet.pdf (accessed on 14 June 2018).

35 Task Force on Climate-Related Financial Disclosures (2017), Recommendations of the Task Force on Climate-related Financial Disclosures i, https://www.fsb-tcfd.org/wp-content/uploads/2017/06/FINAL-TCFD-Report-062817.pdf

${ }^{36} \mathrm{PES}$ is a flexible incentive-based mechanism through which a beneficiary of an ecosystem service (e.g. water retention) pays an individual or community whose land use decisions impact on the provision of that ecosystem service.

${ }^{37}$ OECD-World Bank (2016) Climate and Disaster Resilience Financing in Small Island Developing States.

${ }^{38}$ OECD (2018), Making Blended Finance Work for the Sustainable Development Goals, OECD Publishing, Paris, https://doi.org/10.1787/9789264288768-en.

${ }^{39}$ Ibid.

${ }^{40}$ Campillo, G., M. Mullan and L. Vallejo (2017), "Climate Change Adaptation and Financial Protection: Synthesis of Key Findings from Colombia and Senegal", OECD Environment Working Papers, No. 120, OECD Publishing, Paris, https://doi.org/10.1787/0b3dc22a-en.

${ }^{41}$ For example, InsuResilience, a G7 Initiative on Climate Risk Insurance established under Germany’s G7 presidency in 2017 aims to increase access to direct or indirect insurance coverage against the impacts of climate change for up to 400 million of the most vulnerable people in developing countries by 2020.

42 OECD (2018), Making Development Co-operation Work for Small Island Developing States, OECD Publishing, Paris, https://doi.org/10.1787/9789264287648-en.

${ }^{43}$ OECD (2015) National Climate Change Adaptation: Emerging Practices in Monitoring and Evaluation

${ }^{44}$ Vallejo, L. and M. Mullan (2017), “Climate-resilient infrastructure: Getting the policies right”, OECD Environment

Working Papers, No. 121, OECD Publishing, Paris, http://dx.doi.org/10.1787/02f74d61-en.

${ }^{45}$ Vallejo, L. (2017), “Insights from national adaptation monitoring and evaluation systems”,

www.oecd.org/environment/cc/Insights\%20from\%20national\%20adaptation\%20monitoring\%20and\%20evaluation\%20s ystems.pdf

${ }^{46}$ Vallejo, L. and M. Mullan (2017), “Climate-resilient infrastructure: Getting the policies right”, OECD Environment Working Papers, No. 121, OECD Publishing, Paris, http://dx.doi.org/10.1787/02f74d61-en.

${ }^{47}$ Nicholls, R. et al. (2013), "Planning for long-term coastal change: Experiences from England and Wales”, Ocean Engineering, Vol. 71, pp 3-16, http://dx.doi.org/10.1016/J.OCEANENG.2013.01.025.

48 OECD (Forthcoming), Infrastructure Project Pipelines: Emerging Good Practices in Low-Carbon Investments

${ }^{49}$ OECD (2014), Water Governance in the Netherlands: Fit for the Future?, OECD Studies on Water, OECD Publishing, Paris, http://dx.doi.org/10.1787/9789264102637-en.

${ }^{50}$ OECD (2015), Stakeholder Engagement for Inclusive Water Governance, OECD Studies on Water, OECD Publishing, Paris, http://dx.doi.org/10.1787/9789264231122-en. 


\section{Innovative Approaches to Building Resilient Coastal Infrastructure}

This Policy Paper comprises an Issue Brief and Background Report prepared by the OECD for the G7 Environment, Energy and Oceans Ministers. It outlines the rising risks faced by coastal communities, which are being exacerbated by climate change. It shows how governments can harness innovation in information, planning, financing and monitoring to help improve resilience of those areas to climate change, and emphasises the need for close engagement with coastal communities.

\section{The OECD Environment Policy Paper series}

Designed for a wide readership, the OECD Environment Policy Papers distil many of today's environment-related policy issues based on a wide range of OECD work. In the form of country case studies or thematic reviews across countries, the Papers highlight practical implementation experience.

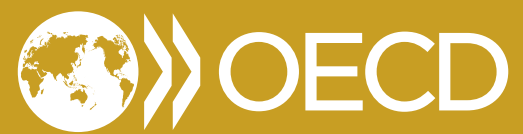

BETTER POLICIES FOR BETTER LIVES
OECD Environment Directorate, September 2018

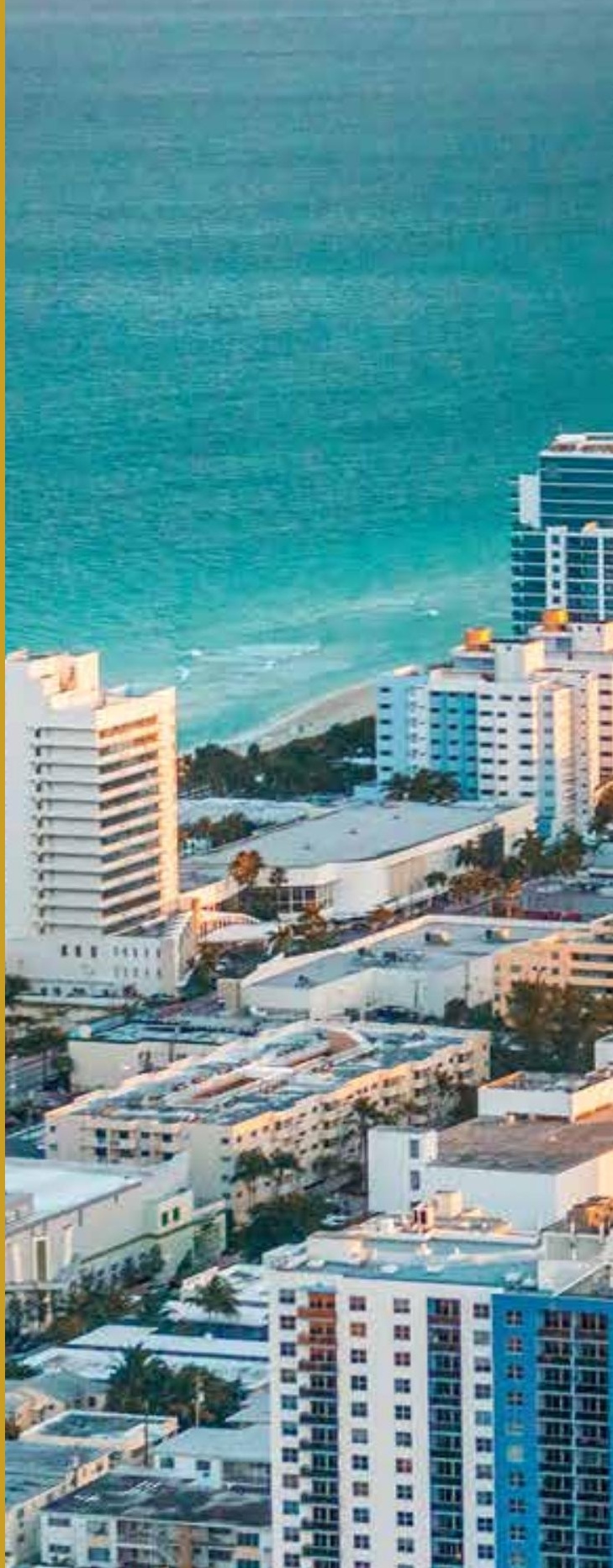

